\title{
Incidental Thyroid Carcinoma Diagnosed after Total Thyroidectomy for Benign Thyroid Diseases: A Prospective Observational Study Ahmed Fayez Othman ${ }^{1}$, Bosat Elwany Bosat ${ }^{2}$, Hamed Ahmad Elbadawy ${ }^{2}$ \\ ${ }^{1}$ General Surgery, Faculty of Medicine for Boys, Al-Azhar University, \\ ${ }^{2}$ Department of General Surgery, Faculty of Medicine for Girls, Al-Azhar University, Cairo, Egypt
}

Correspondence to: Ahmed Fayez Othman, Telephone number: (+20)01002932334, Email: ahmedfayez_666@ yahoo.com

\begin{abstract}
Background: The term "incidental" denotes malignant tumors of the thyroid gland detected postoperative in surgical specimens resected for benign disease. As cancer, thyroid is the commonest endocrine malignancy and their incidence increases over the past 15-20 years. In Egypt, it represents 2.2\% of total cancers. It constitutes $30 \%$ of endocrine malignancies and $12-49 \%$ of head and neck tumors.

Objective: The aim of this study was to determine the incidence and histological features of incidental cancers in patients who had total thyroidectomy for benign thyroid diseases.

Patients and Methods: This Study is a prospective, empirical study carried out at Al-Zahraa University Hospital during the period from April, 2016 to April, 2018. The study included 100 cases had total thyroidectomy of previously diagnosed benign thyroid diseases and fulfilled the inclusion criteria.

Results: In this study, 100 patients underwent total thyroidectomy. The female $(n=86)$ to male $(n=14)$ ratio was 6.14 : 1 and the age ranged from 19 to 69 years. The incidental carcinoma in this study found in 12 (12\%) patients. The frequency of papillary carcinoma was $9 \%$ of all thyroid diseases and $75 \%$ of the incidental thyroid cancer (ITC) (9/12). Also, frequency of follicular carcinoma was $1.4 \%$ of all thyroid diseases (three cases) and $16.66 \%$ of the ITC. Conclusion: The non-irrelevant incidence of ITC, the eventuality of multifocal and bilaterality and the possible occurrence of relapse support that total thyroidectomy without residuum is a valuable option for treating benign thyroid conditions.
\end{abstract}

Keywords: Fine-needle aspiration cytology, Occult, Thyroid swelling, Incidental, Total thyroidectomy.

\section{INTRODUCTION}

Thyroid cancer is the most common endocrine malignancy and there has been a steady increase in its incidence over the past $15-20$ years ${ }^{(\mathbf{1})}$. It accounts for approximately about $1 \%$ of all malignancies in developed countries with an estimated annual incidence of 122,000 cases worldwide ${ }^{(2)}$.

In Egypt, it represents $2.2 \%$ of total cancers. It constitutes $30 \%$ of endocrine malignancies and 12$49 \%$ of head and neck tumors. Most cases occur between 25 to 65 years of age, but it can also occur in very young and in elderly patients ${ }^{(3,4)}$.

Incidental thyroid cancer (ITC) is a malignancy undetected by preoperative imaging studies, but identified by pathological examination of surgical specimens in patients treated for benign thyroid diseases ${ }^{(5)}$. The incidence of ITC ranges between 3 and $16 \%{ }^{(\boldsymbol{6})}$. The mean false-positive and falsenegative rates of the fine-needle aspiration cytology (FNAC) are reported as less than 5\%.

The main limitations of FNAC are the inability of cytology to distinguish follicular and Hürthle cell carcinomas from the respective benign adenomas, the requirement of an experienced prober to avoid non diagnostic punctures and the presence of multiple nodules in a goiter ${ }^{(7)}$.

\section{AIM OF THE WORK}

The aim of this study was to determine the incidence and histological features of incidental cancers in patients who had total thyroidectomy for benign thyroid diseases.

\section{PATIENTS AND METHODS}

Prospective, observational study carried out at Al-Zahraa University Hospital during the period from April 2016 to April 2018. The study included 100 cases subjected to total thyroidectomy for benign thyroid disease. All cases proved to be malignant were excluded from the study.

All patients were subjected to

I. Demographic and Historical Data.

II. Clinical Data.

III. Lab: TSH and Total T4 and T3, Free T4 and T3.

IV. Imaging: Neck ultrasound, Chest $\mathrm{x}$ ray and Computed Tomography (CT) neck.

V. FNA: performed only in cases with a suspicious nodule, which was detected during the clinical examination and on USG.

VI. Indirect laryngoscopy to check the vocal cord movements.

VII. Postoperative histopathologic reports.

Ethical consideration and written informed consent:

An approval of the study was obtained from AlAzhar University academic and ethical committee. Every patient signed an informed written consent for acceptance of the operation. 
Methods: (Operative technique)

Total thyroidectomy

Preoperative Preparation:

All patients undergoing thyroidectomy had preoperative biochemical thyroid function tests as well as a neck ultrasound with fine-needle aspiration biopsies of suspicious nodules. Patients should ideally be euthyroid at the time of operation. Pre-anesthetic evaluation should be a routine step prior to any procedure requiring general anesthesia.

\section{General Principles:}

The following principles apply to all thyroid operations:

1. Good exposure of the thyroid gland is essential for good results.

2. No operation should be performed on the thyroid gland without proper identification of the anatomic structures.

3. Bleeding should be kept to minimum.

4. Diathermy (even bipolar) should be avoided in the area around the laryngeal nerves.

\section{Postoperative assessment:}

The patient was observed in the recovery room for at least 2 hours. The patient was immediately placed in a semi-sitting position. Adequate precautions should be taken to prevent hyperextension of the neck. Oxygen therapy is administered, 4 to $5 \mathrm{~L}$ per minute, until the patient has reacted. Parenteral fluids are given until the patient can take adequate fluids by mouth. Liquids by mouth were permitted as tolerated.

The patients were carefully assessed for the clinical symptoms and signs of complications especially:

- Recurrent laryngeal nerve injury: Immediate postoperative assessment by the anesthetist using direct laryngoscopy is mandatory to assess vocal cords mobility.

- Acute airway obstruction: It may occur immediately postoperatively or in the next few hours due to laryngeal edema.

- Bleeding, hematoma, and ecchymosis: Early postoperative bleeding can occur any time postoperatively. It might be manifested in the suction drain or concealed in the neck due to clot blockage of the drain.

- Hypoparathyroidism (hypocalcemia): The patients were followed up to detect the presence of traces of calcium deficiency and measurement of serum calcium was done for suspicious patients.

\section{Statistical analysis}

Recorded data were analyzed using the statistical package for social sciences, version 20.0 (SPSS Inc., Chicago, Illinois, USA). Quantitative data were expressed as mean \pm standard deviation (SD). Qualitative data were expressed as frequency and percentage.

\section{The following tests were done:}

- Independent-samples t-test of significance was used when comparing between two means.

- Chi-square $\left(\mathrm{x}^{2}\right)$ test of significance was used in order to compare proportions between two qualitative parameters.

- The confidence interval was set to $95 \%$ and the margin of error accepted was set to $5 \%$. The pvalue was considered significant as the following:

- Probability (P-value)

- P-value <0.05 was considered significant.

- P-value <0.001 was considered as highly significant.

- P-value >0.05 was considered insignificant.

\section{RESULTS}

The present study included 100 patients subjected to total thyroidectomy for benign thyroid disease. All patients were subjected to preoperative and postoperative evaluations in the form of clinical, biochemical, radiological, operative, and pathological studies. The incidence was much more common in females (86 patients) than males (14 patients), with a ratio of 6.14: 1 . The ages ranged from 19 to 69 years, with a mean age of $41.79 \pm$ 11.57 years old (Table 1 ).

Table (1). The relation between age, sex and thyroid malignancy

\begin{tabular}{|c|c|c|c|}
\hline & Benign & Malignant \\
\hline & & No. $=88$ & No. $=12$ \\
\hline \multirow{2}{*}{ Sex } & Female(86) & $76(86.4 \%)$ & $10(83.3 \%)$ \\
\hline & Male(14) & $12(13.6 \%)$ & $2(16.7 \%)$ \\
\hline \multirow{2}{*}{ Age } & Mean \pm SD & $42.67 \pm 11.98$ & $37.83 \pm 8.69$ \\
\hline & Range & $19-65$ & $27-69$ \\
\hline
\end{tabular}

The postoperative histopathologic examination of the removed gland showed the presence of ITC in $12(12 \%)$ patients of total number of patients. The incidence of different pathological types of ITC according to preoperative diagnosis is $9(75 \%)$ patients had papillary thyroid cancer (PTC); 2(16.6\%) patients had follicular thyroid cancer (FTC), and one patient had medullary thyroid cancer (MTC) (Table 2). The rest of the $88(88 \%)$ patients had benign thyroid disorders.

Table (2): The relation between Preoperative diagnosis \& Postoperative cancer group 


\begin{tabular}{|c|c|c|c|}
\hline \multirow{2}{*}{$\begin{array}{c}\text { Preoperative } \\
\text { diagnosis }(n=100)\end{array}$} & $\begin{array}{c}\text { Postoperative cancer group } \\
(\mathbf{n}=12)\end{array}$ \\
\cline { 2 - 4 } & PTC & FTC & MTC \\
\hline MNG & 7 & 2 & 0 \\
\hline STN & 2 & 0 & 1 \\
\hline
\end{tabular}

Of 12 patients with ITC, 9 patients $(75 \%)$ has MNG, as compared to 3 patients has STN (25\%) as shown in table (3).

Table (3): Relation between (MNG, STN) in malignant thyroid disease

\begin{tabular}{|l|l|l|l|l|}
\hline \multirow{2}{*}{ Neck US } & \multicolumn{2}{|c|}{ Benign } & \multicolumn{2}{c|}{ Malignant } \\
\cline { 2 - 5 } & No. & $\%$ & No. & $\%$ \\
\hline MNG(n=82) & 73 & $83 \%$ & 9 & $75 \%$ \\
\hline $\operatorname{STN}(n=18)$ & 15 & $17 \%$ & 3 & $25 \%$ \\
\hline
\end{tabular}

The distribution of ITC according to preoperative diagnosis was $10(83.3 \%)$ patients with euthyroid state and two patients (16.7\%) patients with controlled toxic goiter (Figure 1).

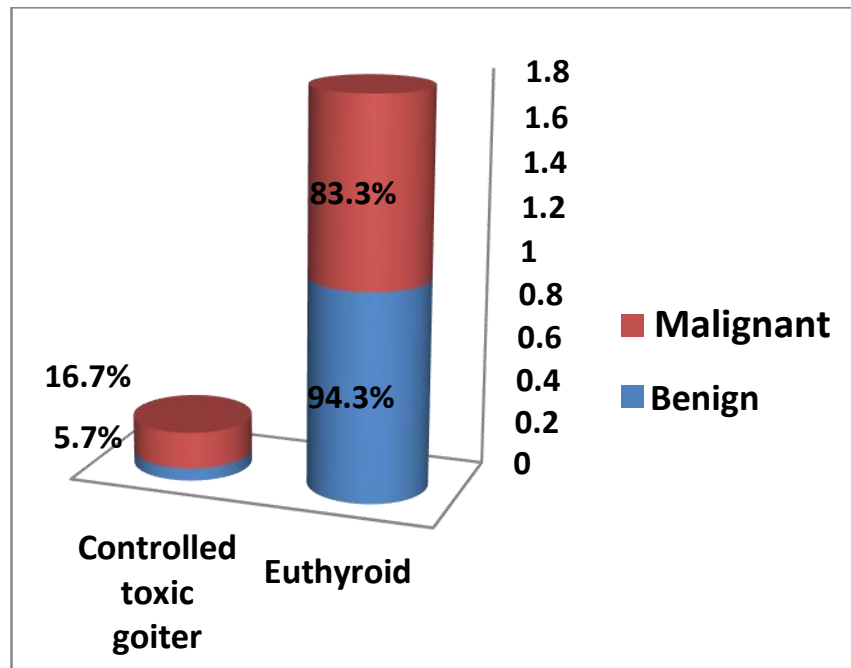

Figure (1): Relation between thyroid profile and thyroid malignancy.

Nodule size was reported ultrasonographically for all cases using the maximum diameter given for each nodule and sub-classifying nodules into three groups $(<2 \mathrm{~cm})(2-4 \mathrm{~cm})(>4 \mathrm{~cm})$. The highest incidence of malignancy (50\%) was found between cases with the size of a nodule $(2-4 \mathrm{~cm})$. The mean size of nodule in this study $2.56 \pm 1.23 \mathrm{~cm}$. The mean size of malignant nodules $2.85 \pm 1.43$, the mean size of benign nodules $2.50 \pm 1.18$ (Table 4 ).

Table (4): Relation between nodule size and pathology $(n=100)$

\begin{tabular}{|c|c|c|c|c|}
\hline \multirow{2}{*}{} & \multicolumn{4}{|c|}{ Pathology } \\
\cline { 2 - 5 } & \multicolumn{2}{|c|}{$\begin{array}{c}\text { Benign } \\
(\mathbf{n = 8 8})\end{array}$} & \multicolumn{2}{c|}{$\begin{array}{c}\text { Malignant } \\
(\mathbf{n = 1 2})\end{array}$} \\
\cline { 2 - 5 } & $\mathrm{N}$ & $\mathbf{\%}$ & $\mathrm{N}$ & $\mathbf{\%}$ \\
\hline $\begin{array}{c}\text { Size of nodule } \\
(\mathbf{n = 1 0 0})\end{array}$ & & & & \\
\hline$<2 \mathrm{~cm}(\mathrm{n}=39)$ & 35 & $39.7 \%$ & 4 & $33.3 \%$ \\
\hline $2-4 \mathrm{~cm}(\mathrm{n}=42)$ & 36 & $40.9 \%$ & 6 & $50 \%$ \\
\hline$>4 \mathrm{~cm}(\mathrm{n}=19)$ & 17 & $19.3 \%$ & 2 & $16.6 \%$ \\
\hline
\end{tabular}

Cervical LNs suspicious found in 11 (11\%) patients. Three patients out of $11(27.3 \%)$ with suspicious LNs had been proved to be malignant (Figure 2).

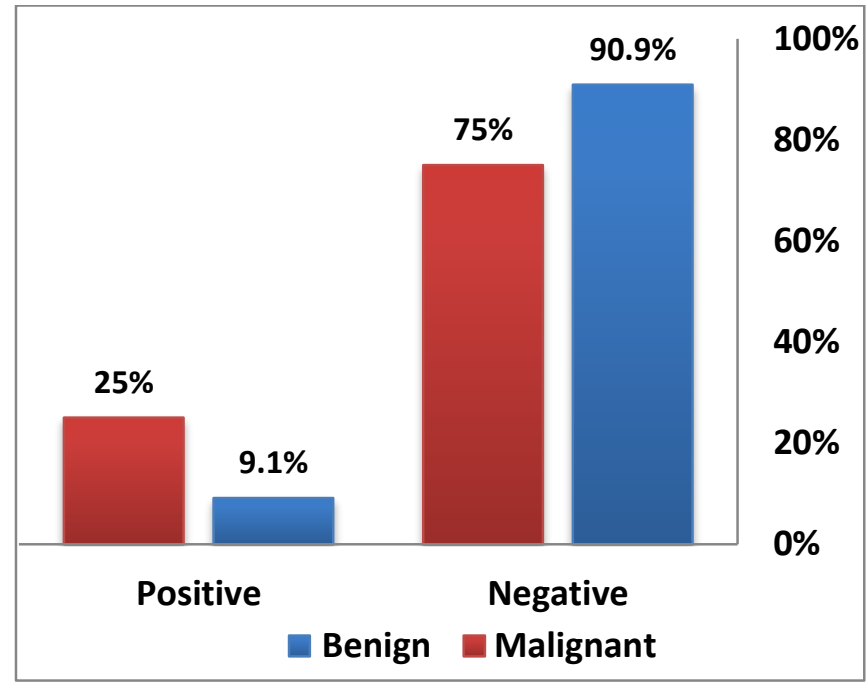

Figure (2): Cervical LN by US.

Retrosternal extension found in 8 patients and 92 patients without retrosternal extension. One of malignant patients $(8.3 \%)$ had retrosternal extension, other 11 patients $(91.7 \%)$ without retrosternal extension as shown in table (5).

Table (5): Relation between the presence of retrosternal extension (RSE) and malignancy

\begin{tabular}{|c|c|c|c|c|}
\hline \multirow{2}{*}{$\begin{array}{c}\text { Retrosternal } \\
\text { extension }\end{array}$} & \multicolumn{2}{|c|}{ Benign } & \multicolumn{2}{c|}{ Malignant } \\
\cline { 2 - 5 } & No. & $\%$ & No. & $\%$ \\
\hline Negative(n=92) & 81 & $92.1 \%$ & 11 & $91.7 \%$ \\
\hline Positive $(n=8)$ & 7 & $7.9 \%$ & 1 & $8.3 \%$ \\
\hline
\end{tabular}

From 100 patients in this study, 8 patients $(8 \%)$ were complicated postoperatively, in the form of hypoparathyroidism, recurrent laryngeal nerve injury (RLN), external laryngeal nerve injury (ELN), hemorrhage, infection (Table 6).

Table (6): Frequency of Complications

$$
\begin{array}{l|l}
\text { Complication } & \text { N (\%) }
\end{array}
$$




\begin{tabular}{|l|l|}
\hline Hypoparathyroidism & $\mathbf{2}(\mathbf{2 \%})$ \\
\hline Recurrent laryngeal nerve injury & $\mathbf{2 ( 2 \% )}$ \\
\hline External laryngeal nerve injury & $\mathbf{1 ( 1 \% )}$ \\
\hline Hemorrhage & $\mathbf{1 ( 1 \% )}$ \\
\hline Infection & $\mathbf{2 ( 2 \% )}$ \\
\hline Total & $\mathbf{8 ( 8 \% )}$ \\
\hline
\end{tabular}

\section{DISCUSSION}

The present study included 100 patients subjected total thyroidectomy for benign thyroid disease. From this study, the female (86) to male (14) ratio was 6.14:1, and their ages ranged from 19 to 69 years old, with a mean age of $41.79 \pm 11.57$ years. The median age was $42.67 \pm 11.98$ years and $37.83 \pm 8.69$ years in benign and malignant thyroid diseases respectively. Men had a higher malignancy rate $(14.28 \%)$ than women $(11.6 \%)$.

According to this study, the correlation of age and sex in relation to incidence of Incidental Thyroid Carcinoma was not found to be statistically significant $(p>0.05)$. Similar observations are noted in other studies of Himabindu $\boldsymbol{e t}$ al. ${ }^{(8)}$ and Salmaslioglu $\boldsymbol{e t}$ al. ${ }^{(9)}$. Other study of Frates (10) found that the incidence of thyroid carcinoma on the final pathologic assessment were higher in older age and male gender patients. On the other hand, study of Luo et al. ${ }^{\text {(7) }}$ found younger male patients were reported to be associated with a significantly higher risk of malignancy. From the previously mentioned studies, it is clearly known that there is a great conflict about the correlation between age and gender, and the incidence of thyroid malignancy, probably due to a difference in patient's selection and numbers of the study population (10,11, 12 and 13).

In our study, the incidental carcinoma was found in $12(12 \%)$ patients. Nonmalignant thyroid diseases were seen in $88(88 \%)$ patients. These results are similar to the results of Krishna et al. ${ }^{(14)}$ which studied 42 patients who underwent thyroidectomy for benign thyroid disease, and the final histology revealed ITC in $12 \%$ out of the total 42 patients. These results also are similar to the results of Faisal $\boldsymbol{e t} \boldsymbol{a l}$. (15), which studied 211 patients who underwent thyroid surgery, and the final histology revealed ITC in $22(10.4 \%)$ patients. Also these results are similar to the results of Costamagna et al. ${ }^{(17)}$, which revealed ITC in $53(9.3 \%)$ patients out of 646 patients. Askitis et al. ${ }^{(21)}$ revealed ITC in 33 (14.5\%) of 228 patients. Also, these results are similar to the results of Miccoli et al. ${ }^{(6)}$, which studied 998 patients who underwent thyroidectomy for benign thyroid disease, and the final histology revealed ITC in 104 (10.4\%) patients.. These small differences may be owing to their selection of patients who underwent only total thyroidectomy. In a study by Harach et $\boldsymbol{a l} .{ }^{(17)}$, the incidence ranged from 3-36\%.
Our study showed that the incidence of papillary carcinoma in unsuspected cases was $9 \%$ of all thyroid diseases, that of the 12 patient with ITC, 9 (75\%) patients had papillary thyroid cancer. Of the 22 patients with ITC, $18(81.8 \%)$ patients had papillary thyroid cancer in a study done by Faisal et al. ${ }^{(15)}$, These results are close to the results of Askitis et al. ${ }^{(18)}$ where their study showed that papillary thyroid carcinoma had the highest incidence (27 from 228), representing $11.8 \%$ of thyroid diseases and $81.8 \%$ of ITC (27/33). In a study by Miccoli et al. ${ }^{(6)}, 95.2 \%$ of patients presented with papillary carcinoma. Papillary carcinoma was found to be the commonest (75\%) in a series by Memon et al. ${ }^{(19)}$.

Our study showed that the frequency of follicular carcinoma was $2 \%$ of all thyroid diseases (two cases), and $16.6 \%$ of ITC. These results are close to the results of Faisal et al. ${ }^{(15)}$ and Askitis et al. ${ }^{(18)}$.

Our study showed that there was just one case that had medullary thyroid cancer $(1 \%$ of thyroid diseases and $8.3 \%$ of ITC). These results are close to the results of Askitis et al. ${ }^{(18)}$, as they found 2 cases had undifferentiated thyroid cancer, representing $6.1 \%$ of ITC. The study by Nanjappa et al. (20) enclosed 187 cases that underwent thyroidectomy for benign thyroid disease and found no cases of anaplastic, medullary thyroid cancer, or lymphoma.

The studied population included 93 Euthyroid state (93\%) and 7 Controlled toxic goiter (7\%). 10 Euthyroid cases (83.3\%) proved to be malignant, as compared to 2 cases in controlled toxic goiter $(16.7 \%)$. The difference was not statistically significant.

The studied population included 82 cases of MNG ( $82 \%)$ and 18 cases of STN (18\%). The final histopathology proved to be malignant in 9 MNG patients (75\%), as compared to 3 in STN (25\%). So the incidence of malignancy between our STN cases was $16.66 \%$ and between our MNG cases was $10.97 \%$. This study revealed that patients with MNG have the risk of malignancy as those with STN.

In study by Gelmini et al. ${ }^{(21)}$ analyzing ITC in MNG and STN showed that ITC in MNG were $12.6 \%$ and in STN $6.8 \%$. Another study showed that the incidence of carcinoma in MNG was not significantly different from carcinoma in STN (22). Koh (23) reported $7.5 \%$ patients with MNG had carcinoma. In Costamagna et al. (16) study, 85\% of ITC were preoperatively diagnosed as MNG and $15 \%$ of ITC were preoperatively diagnosed as STN. Traditionally, it is considered that the incidence of carcinoma is higher in solitary cold nodule (22). However, multinodularity cannot be considered as a certain indicator of benign thyroid disease (24).

Retrosternal extension found in 8 patients and 92 patients without retrosternal extension. One among malignant patients $(8.3 \%)$ had retrosternal extension, other 11 patients $(91.7 \%)$ without retrosternal 
extension. Therefore, there was no statistically significant difference in malignancy occurrence between patients with retrosternal extension (RES)

According to the ATA Guidelines from 2015, ITC detected on histopathologic examination of thyroid tissues removed for MNG or another benign disease does not need more treatment if total or near total thyroidectomy has been performed ${ }^{(25)}$.

\section{CONCLUSION:}

The findings of this study favors a lot of radical, aggressive therapeutic management in patients with a probability of benign thyroid disease. In spite of detailed preoperative evaluation, carcinomas of thyroid are detected incidentally in postoperative biopsy specimens of some patients operated for benign thyroid diseases which has oncological significance. As detection of small lesions preoperatively is still insufficient despite the improvement of diagnostic methods for thyroid gland (ultrasonography, and UG-FNAB), which can detect thyroid nodules between 1 and $2 \mathrm{~mm}$ in size.

The results of this study confirmed that the frequency of ITC in patients who underwent surgery for benign thyroid diseases are not negligible. Our data also showed that the possibility of missing a malignant neoplasm existed in patient's regardless size of nodules in the case of multinodular goiter.

The incidence of ITC is not significantly different between patients presenting with SNG and MNG. FNAC is inconclusive and suggests that FNAC be performed under ultrasound guidance and multiple aspirations be done in patients with MNG not only in dominant nodules but also in all other nodules appearing. However, a larger study is needed to draw definite conclusions.

The prevalence of ITC on postoperative histopathologic examination makes us tend to do a total thyroidectomy in patients with benign thyroid diseases to avoid leaving residual unhealthy thyroid tissue liable for recurrence with or without superimposed malignancy to avoid the necessity for reoperation. In addition, the risk of complications in the secondary surgical intervention is extremely high. REFERENCES

1. Suliburk J, Delbridge L (2015): Surgical management of well-differetiated thyroidcancer: state of the art. Surg Clin N Am., 89: 1171-1191.

2. Sherman SI (2013): Thyroid carcinoma. Lancet, 361(9356): 501-11.

3. Elattar I (2004): Cancer in Arab world: Magnitude of the Problem. The $132^{\text {nd }}$ annual meeting. Available at: http://www.nci.edu.eg/ lectures/cancer_problem/Cancer.

4. El-Bolkainy MN, Nouh A, El-Bolkainy TN (2005): Topographic pathology of cancer. Egypt: NCI, Cairo University. NCI publication in PubMed_Book_1.

5. Ito Y, Higashiyama T, Takamura Y et al. (2007): Prognosis of patients with benign thyroid disease accompanied by incidental papillary carcinoma undetectable on preoperative imaging tests. World J Surg., 31: 1672-6.

6. Miccoli P, Minuto MN, Galleri D et al. (2006): Incidental thyroid carcinoma in a large series of consecutive patients operated on for benign thyroid disease. ANZ J Surg., 76: 123-6.

7. Luo J, McManus C, Chen H et al. (2012): Are there predictors of malignancy in patients with multinodular goiter? J Surg Res., 174: 207-210.

8. Himabindu N, Rama MV, Bhargavi M (2019): Incidental Thyroid Carcinoma-A Surgical Dilemma. International Journal of Scientific Research. http://worldwidejournals.co.in/index.php/ijsr/article/v iew/861/0

9. Salmaslioglu A, Erbil Y, Dural C et al. (2008): Predictive value of sonographic features in preoperative evaluation of malignant thyroid nodules in a multinodular goiter. World J Surg., 32(9): 194854.

10. Frates MC, Benson CB, Doubilet PM et al. (2006): Prevalence and distribution of carcinoma in patients with solitary and multiple thyroid nodules on sonography. J Clin Endocrinol Metab., 91(9): 3411-7.

11. Gharib H, Papini E, Paschke $R$ et al. (2010): American Association of clinical Endocrinologists, Associazione Medici Endocrinologi, and European Thyroid Association medical Guidelines for clinical practice for the diagnosis and management of thyroid nodules. Endocrine Practice, 16: 1-43.

12.Cooper DS, Doherty GM, Haugen BR et al. (2009): Revised American Thyroid Association management guidelines for patients with thyroid nodules and differentiated thyroid cancer. Thyroid, 9: 1167-1214.

13. Corrias A, Einaudi $S$, Chiorboli $\mathbf{E}$ et al. (2001): Accuracy of fine needle aspiration biopsy of thyroid nodules in detecting malignancy in childhood: comparison with conventional clinical, laboratory, and imaging approaches. J Clin Endocrinol Metab., 86(10): 4644-8.

14. Krishna M, Kavita T, Shashi K (2019): Study of incidence of occult thyroid carcinoma in patients operated for benign thyroid disease. International Journal of Scientific Research, 6: 2277 - 8179.

15. Faisala M, Fathya H, Risk A et al. (2018): Incidental thyroid carcinoma after thyroidectomy for benign thyroid disease in Suez Canal region. The Egyptian Journal of Surgery, 37: 361-367.

16. Costamagna D, Pagano L, Caputo M et al. (2013): Incidental cancer in patients surgically treated for benign thyroid disease. Our experience at a single institution. G Chir., 34: 21-26.

17. Harach HR, Franssila KO, Wasenius VM (1985): Occult papillary carcinoma of the thyroid. A "normal" finding in Finland. A systematic autopsy study. Cancer, 56(3):531-8.

18. Askitis D, Efremidou EI, Karanikas M et al. (2013): Incidental thyroid carcinoma diagnosed after total thyroidectomy for benign thyroid diseases: incidence and association with thyroid disease type and laboratory markers. Int J Endocrinol., 2013: 45159.

19. Memon W, Khanzadaa TW, Jamad A et al. (2010): Incidence of thyroid carcinoma in multi-nodular 
goiter. Rawal Med J., 35(1): 65-67.

20. Nanjappa N, Kumar A, Swain SK et al. (2013): Incidental thyroid carcinoma. Indian $\mathbf{J}$ Otolaryngol Head Neck Surg., 65: 37-39.

21. Gelmini R, Franzoni C, Pavesi E et al. (2010): Incidental thyroid carcinoma (ITC): a retrospective study in a study of 737 patients treated for benign disease. Ann Ital Surg., 81: 421-427.

22. McConahey WM, Hay ID, Woolner LB et al. (1986): Papillary thyroid cancer treated at the Mayo Clinic. 1946 through 1970: initial manifestation, pathologic findings, therapy and outcome. Mayo Clin Proc., 61(97): 48-96.
23. Koh KB and Chang KW (1992): Carcinoma in MNG. Br J Surg., 79(3): 266-7.

24. Pelizzo MR, Toniato A, Piotto A et al. (1996): Cancer in multinodular goiter. Ann Ital Chir., 67(3): 351-6.

25. Haugen BR, Alexander EK, Bible KC et al. (2016): 2015 American Thyroid Association Management Guidelines for Adult Patients with Thyroid Nodules and Differentiated Thyroid Cancer: The American Thyroid Association Guidelines Task Force on Thyroid Nodules and Differentiated Thyroid Cancer. Thyroid, 26(1): 1-133. 